\title{
EDITORIAL
}

\section{GRANDES DESAFÍOS}

La Revista Chilena de Radiología es la publicación oficial de la Sociedad Chilena de Radiología, y como tal es la manifestación de nuestro accionar en el mundo radiológico. En los últimos años, bajo la dirección de la Dra Karla Moënne, ha continuado su expansión a la comunidad hispano hablante, y ha extendido su conocimiento al exterior. He visto en estos años, como miembro del Comité Editorial, el enorme esfuerzo que ha colocado en esta tarea, y he sido testigo de la labor desinteresada que ha cumplido para lograrlo.

Se me ha solicitado que asuma la coordinación del proceso editorial de la Revista Chilena de Radiología. He aceptado ese desafío, honrado por la designación y con la esperanza de poder seguir esta senda trazada. Es un trabajo enorme, que se realiza en conjunto con el Comité Editorial, y donde la participación de la comunidad radiológica como revisores, y como contribuyentes de trabajos, es fundamental.

Tenemos una serie de desafíos ante nosotros como comunidad. En primer lugar, la internacionalización de nuestra Revista se ha hecho patente al estar incluida en SciElo. Ello ha permitido que el acceso a nuestro quehacer científico sea visible también más allá de nuestras fronteras. Implica también que podemos ampliar nuestros horizontes y buscar que cada vez más colegas se interesen en nuestra publicación, la consulten y les sea de utilidad. Para ello, debemos buscar producir trabajos de calidad, y orientados a resolver los problemas del día a día de nuestra especialidad. Grandes avances se hacen en esta área y vemos como cada año, en los Congresos realizados en nuestro país, las presentaciones son de mayor número y calidad.

En segundo lugar, debemos trabajar en optimizar y mejorar el proceso editorial, de forma de poder facilitar el envío de artículos para revisión, la revisión expedita y cómoda de ellos por los revisores especialistas, y brindar respuesta oportuna respecto de la decisión editorial de publicación a los autores. Por ello, mantendremos el trabajo iniciado para profesionalizar este proceso, y lograr brindar una plataforma electrónica donde se pueda acceder a éste, como la que disponen las grandes revistas del área.

Tenemos también una consideración adicional, cual es que nuestra especialidad se encuentra en un punto crucial de su desarrollo. Una especialidad que está en crecimiento constante, que incorpora nueva tecnología a un ritmo vertiginoso, y que es pieza fundamental de los procesos diagnósticos modernos, nos plantea nuevos desafíos. Debemos ser capaces de responder con conocimiento y certeza a las exigencias de nuestros equipos de trabajo, conocer las fortalezas y debilidades de cada una de nuestras técnicas diagnósticas y ser referentes e interconsultores de todos los aspectos relacionados a los diagnósticos por imágenes. Sólo de esa forma podemos validarnos dentro de nuestros grupos de trabajo (hospitales, centros médicos, y otros).

Por último, invitar a todos los colegas y a los residentes, a participar activamente en la Revista Chilena de Radiología, a sentir que ésta es Nuestra Revista, un reflejo de lo que hacemos en el país. Mostrar cómo hemos avanzado en el tiempo, y disponiendo de mayor tecnología, somos capaces de plantearnos más allá de solamente la producción, y abrir un espacio de generación de conocimiento. Nuestras realidades y patologías locales son distintas a la de otros países que publican más, por lo que el enfrentamiento que hagamos a ellas puede ser más ingenioso o más asertivo que lo ya descrito por otros. Quedan planteados los desafíos que tenemos por delante como comunidad. La materia prima está, sólo queda trabajarla.

\author{
Dr. Claudio Silva Fuente-Alba \\ Médico Radiólogo \\ Futuro Editor Revista Chilena de Radiología
}

